\title{
The Importance of The Attractions for Historical, Cultural and Natural Resources U-thong District, Suphanburi Province
}

\author{
Wittaya Wisutruangdat \\ Faculty of Humanities and Social Science,Bansomdejchaopraya Rajabhat University \\ wit_wittaya@hotmail.com
}

\begin{abstract}
The purpose of this research was to study the importance of attractions for historical, cultural and natural resources U-thong district, Suphanburi Province. The population of the study consisted of experts and people involved with the attractions. Qualitative method was designed. Qualitative data was collected from 12 key informants and was analyzed by using content analysis. Results indicated that U-thong district had many attractions and can be divided into 3 groups as follows. 1) The historical tourism has been shown 3 sites in 2 sub-districts: 1.1) U-thong had Wat Khan ThamThiam, Wat Khao Phra Si Sanphetchayaram and U-thong National Museum. 1.2) Chorakae Sam Phan had Wat Khao ThamSua. 2) The cultural tourism has been shown 4 sites in 3 sub-districts. 2.1) U-thong has had Chao pho phrayachak shrine and Ban Khok. 2.2) Don Makuek had Ban Don Makuek weaving group. 2.3) Ban Don had an ancient black tai cultural restoration center. 3) Natural Resource Tourism has been shown 3 sites in 2 sub-districts. 3.1) U-thong has had Phu Hang Nak rock park and Phu Muang forest park. 3.2) Phapphachai had agricultural extension and development center. The suggestions of this study were 1) there should be more publicity for tourist attractions in U-thong district, and 2 coordinate various departments in supporting tourism in U-thong district.
\end{abstract}

Keywords

The Attractions, U-thong District, Suphanburi Province.

Article Received: 10 August 2020, Revised: 25 October 2020, Accepted: 18 November 2020

\section{Introduction}

U-thong used to be an important city. Which has traces of the ancient community from time to time, but the prehistoric period continues until the time of Dvaravati culture from India. Used to be a center of ancient trade linking between the Andaman sea and the gulf of Thailand. Correspond to [1] and[2] said the ancient city of u-thong was a city that had Indian culture. Including trade that distributed in many areas in different areas. This location of the community and traces of ancient civilizations. Correspond to [3] said U-thong was an important city, where a Roman coin was unearthed in the 3 rd century and had a mooring point between the river used to be a trade route. The people in this area were rich. There was jewelry such as gold beads known as Suvarnabhumi. Today u-thong is an ethnically diverse area of indigenous such as Thai, Thai Song Dam, Thai Phuan, Thai Chinese, Lao Wiang and Lao Khang, but [4] said u-thong district has had 5 ethnic groups:Thai, Thai Song Dam, Thai Chinese, Lao Wiang and Lao Khang. However,ethnicity has interested traditions within their identity. That can be used as a cost to generate income for various communities, including within u-thong district. There have been also various tourist attractions by many other natural sources. That has been still abundant can incentivize tourists to come visitconsistent to [5] said community-based tourism can stimulate the economy at the foundation level, creating jobs, income distribution to the community,solving the problem of poverty.

Attractions within $U$ Thong District has been important place of history, culture and natural resources. Whichhas had long story. And worthy of conservation.For this reason, it has made me interested in studying the importance of the attractions for historical, cultural and natural resources Uthong District, Suphanburi Province.

\section{Research Objective}

The objective of this research article was to study the importance of the attractions for historical, cultural and natural resources u-thong district, suphanburi province.

\section{Research Methods}

\section{A. Research design}

Qualitative research used research tool was interview. Data collected from in-depth interview. Qualitative data from 12 key informants analyzed by using content analysis. The process of implementation consisted of1) Documentary study from primary sources including story of attractions of u-thong district, suphanburi provinceand other related documents. 2) an area study of understanding community. 3) Studied spatial data through in-depth interviews and observed within the area. 4) The obtained data analyzed by triangulation and 5) Research finding.

\section{B. Research Process}

Research process of this research had 5 steps consisted of to analyze concept, created research tools, conduct the experiment, and to assess experimental results. Steps were shown in Fig. 1. 
Research Process

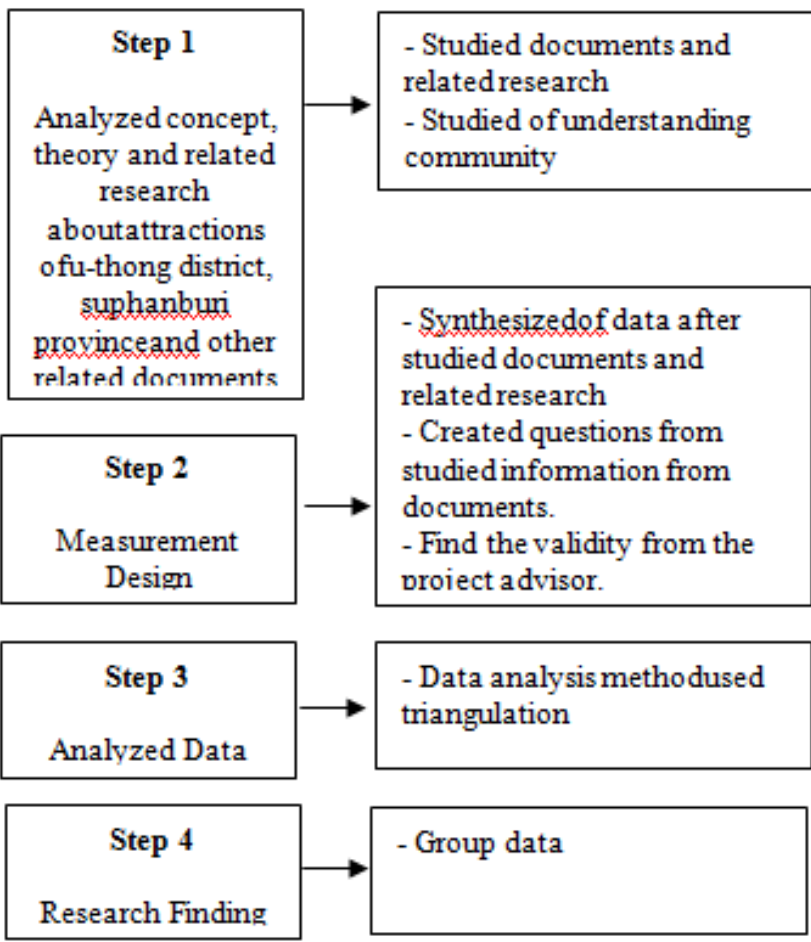

Fig.1 Research process for analyzed the importance of the attractions for historical, cultural and natural resources uthong district, suphanburi province

\section{Results}

The research found u-thong district, there were many attractions. Can be divided into 3 groups as follows.

1. Historical tourism referred to tourism that focuses on the history of the community and tourist attractions in u-thong district, consisting of

\subsection{Wat Khan Tham Thiam}

Located at u-thong subdistrict, u-thong district, suphanburi Province. It was an ancient temple from ancient times. With the assumption that it may be the first temple in Thailand. Which after 300 years of the lord buddha's death. The lord buddha's death has made a third amendment with king ashoka at the city of patali. He sent diplomats out to various places with phrasona and phrauttarathera spreading Buddhism to Suvarnabhumi. They inscribed in the ancient Sanskrit that pushaya Kiri or pusakhiri meant mountain flowers because the mountain had beautiful flowers.

On top of wat khan tham thiam has a cave. Which was received in 1928. If you walk up to the top of that you will find a small old temple with a door into one side. Near each other there is a chedi in the Ayutthaya period and as a point to watch the sunset as well.

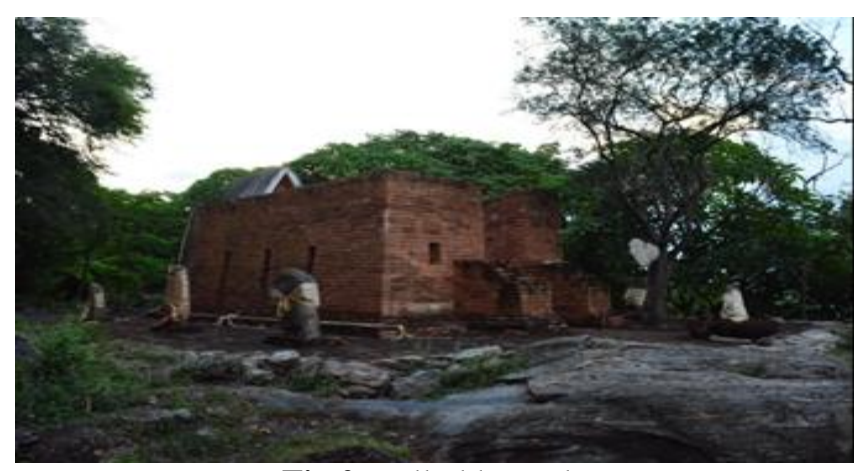

Fig.2small old temple

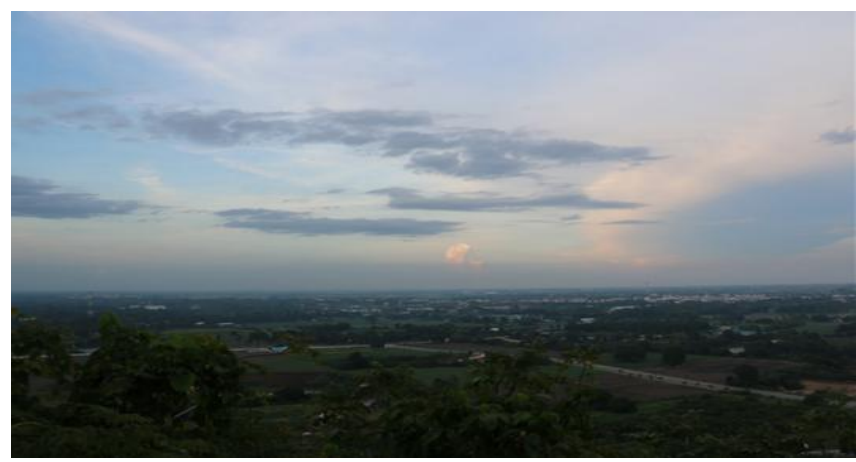

Fig.3 Sunset point

1.2 Wat khao phrasisanphetchayaram

Located on winyanuyokrd, u-thong subdistrict, u-thong district, suphanburi province. It was old temple has existed since the Dvaravati period. Before u-thong city flourished. There were also old objects. Many pieces were evidence in the composition, such as buddha amulets, phirod Buddha amulets, reclining buddha images, hermit images as a form of Dvaravati. Most of them were broken, leaving only the heads. Some buddha image had not head. The collected part was collected from the back of the great reclining Buddha. Which the general villagers call "loung pho sang sisanphet" On top of Wat khao phrasisanphetchayaramhas phramonthop enshrines a replica of the buddha's footprint make from natural green stone and the remains of 1 Ayutthaya period pagoda

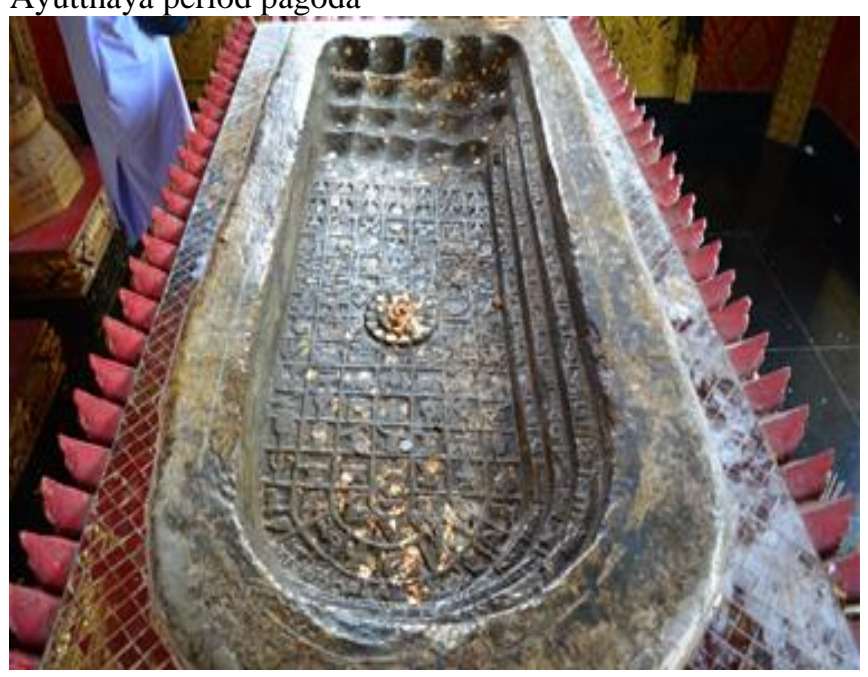

Fig.4the buddha's footprint 


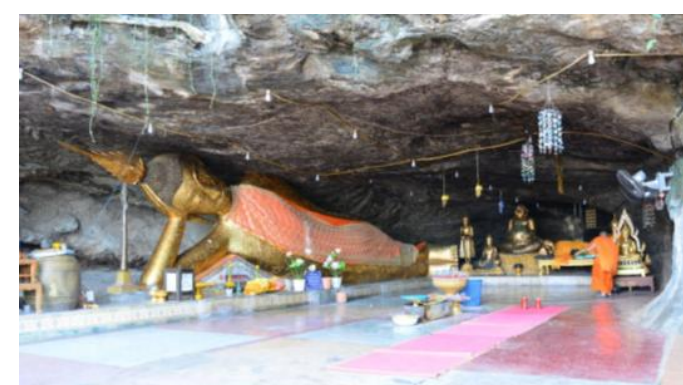

Fig.5loung pho sang sisanphet

\subsection{U-thong national museum}

Located on malaimanrd, u-Thong subdistrict, u-thong District, suphanburi. Operated since 1959. U-thong national museum had 2 buildings.

Building 1 has shown exhibition on the ancient city of $\mathrm{u}$ thong and Dvaravati culture has divided into 2 rooms.

Room 1 has been a room that exhibits prehistoric antiques and the development of the ancient city u-thong. Which found evidence of human habitation since prehistoric. Society during that time was an agricultural society. It has been considered to be during the Neolithic period and continued to the metal age. And ancient evidence that has shown u-thong ancient city used to be a major trading hub for the ancient communities in the region.

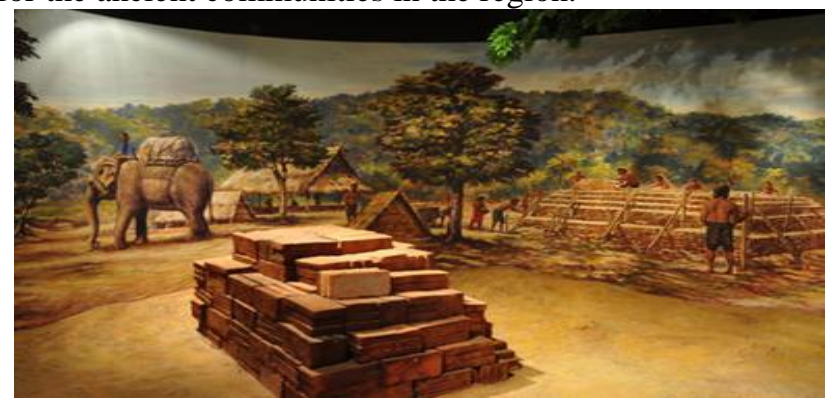

Fig.6 Agricultural society

Room 2 has shown the story and importance of the ancient city of u-thong as the early historical city of Thailand. It was once a commercial center and a center for buddhism before spreading prosperity to other ancient and contemporary communities. So Important antiques on display include Dhammachak, stone, bronze buddha image, terracotta buddha images, etc.

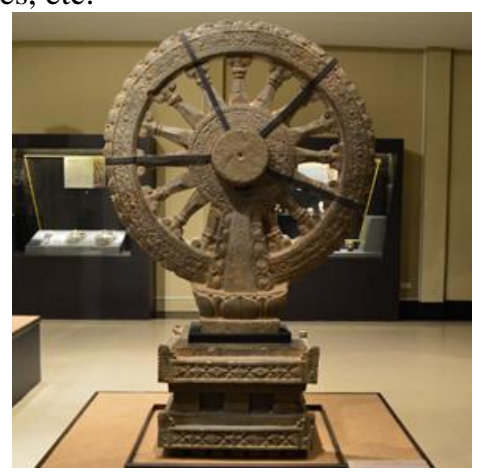

Fig.7Dharmachak stone

Building 2 has been permanent exhibition about the land of Suvarnabhumi, historical development of the ancient city of u-thong, Sea trade routes and the ancient city of u-thong as the center of Buddhism has divided into 2 rooms.

Room 1 has shown the historical developmentof the land of Suvarnabhumi, important commercial sources of the ancient world and trade between various ancient communities both inside and outside with antiques and media exhibits various types of modern.

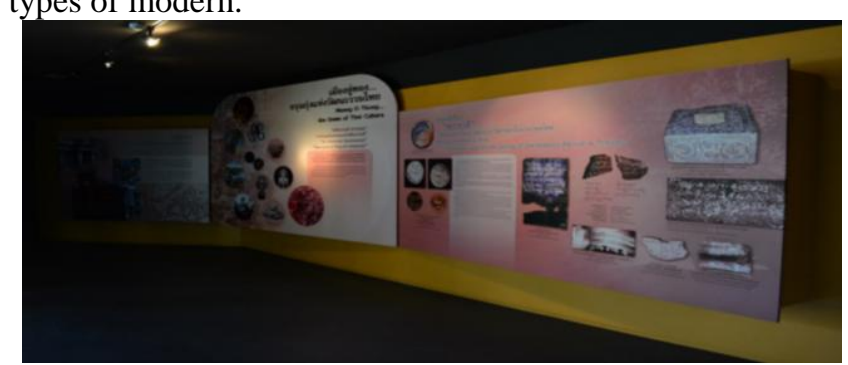

Fig.8 Display room sign

Room 2 has shown simulate the maritime trade event from the Indian Peninsula to the land of Suvarnabhumi some 3,000 years ago, the maritime of foreign merchants and major trade routes and port at that time. Which has believed that part of the trade route with the ancient u-thong city.

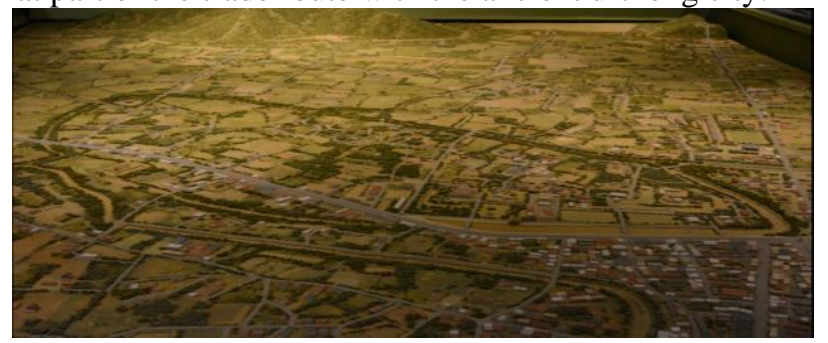

Fig.9 Ancient U Thong City Plan

\subsection{Wat khao thamsua}

Located on chorakhesam phan subdistrict, u-thong district, suphanburi. Wat khao thamsua has sacred archaeological site. Which was before Wat khao thamsua. This area has unearthed many ancientpagodas. In which each chedi has had many valuable antiques. Currently, only the base of the pagoda cannot be assumed. The cause of the collapse has come from two reasons: 1) from time and 2) human destruction due to excavation of antiques in the pagoda, but with a quiet atmosphere and it has been good place for meditation. Causing monks has come to Buddhist lest in order to practice themselves until the creation of a monastery.

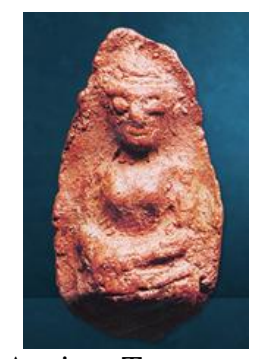

Fig.10 Ancient Terracotta Monks

2. Cultural tourism referred to tourism that focuses on the studied of old ways of life in u-thong district, consisting of 


\subsection{Chao pho phrayachak shrine}

Located near u-thong subdistrict municipal market, u-thong Subdistrict, u-thong district, suphanburi province.

History of chao pho phrayachak has been an idol of Vishnu during Dvaravati period. Made of laterite and engraved with embossing. The $\mathrm{u}$-thong people found this image around the year 1857. This idol has floated through the chorakhesam phan river. They brought out of the water and built a shrine for the villagers to worship. Cause called "chao pho phrayachak" because the u-thong people saw Vishnu with four hands and hold the chakra in his hand. Characteristics of the shrine built as a Chinese shrine because there have been many Chinese people in the u-thong market.

In the middle of the night on August 29, 1967, a fire at the shrine. But idol of Vishnu was not damaged. Causing the villagers in that area to have faith. Worshiping brings happiness, good trade and a safe journey.

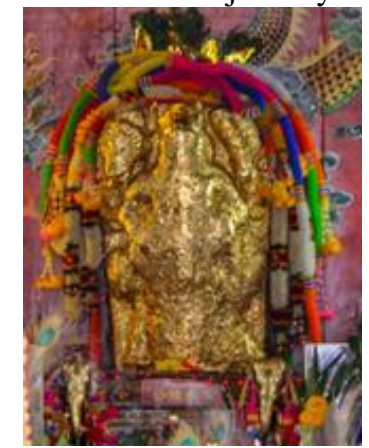

Fig.11chao pho phrayachak

\subsection{Ban khok}

Located at u-thong subdistrict, u-thong district, suphanburi province. This has been where Lao Khrang people live. Who emigrated from Laos in the reign of Rama 3 until Rama 5, then has come here. Lao Khrang's way of life is simple. There are two interesting things in the community:

\subsubsection{Antique bicycle museum}

Ban khok people has been farmers. When the product has obtained. It will be sold to the market. Often used bicycles to sell products. Headman of ban khok kept the old bicycles. Some bicycle are over 100 years old. There have been many activities for tourists.

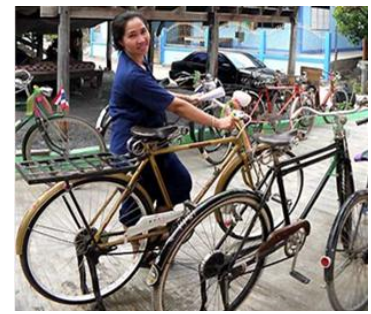

Fig.12Antique bicycle

\subsubsection{Ho chaw nai}

Lao Khrang people have long respected ghosts.Causing the ban khok people has preserved traditionalculture. Where the place of performing the ceremonyhas called "ho chaw nai" has been an important sacred place of the village. It has been an open courtyard at the front ant the end there has been big trees. Near has been the location of 7 small shrines, arranged in a row in front of the board. ho chaw nai has been a place to seize the minds of the ban khok people.

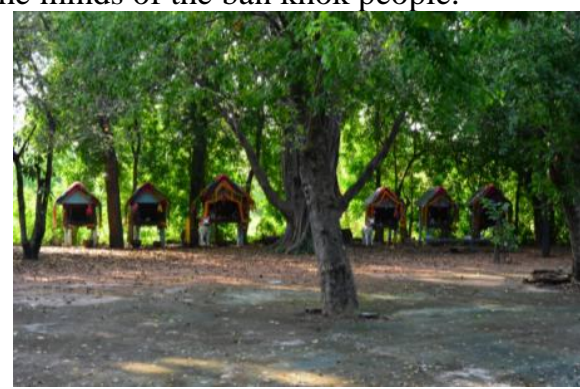

Fig.13Ho chaw nai

\subsection{Ban don makuek weaving group}

Located at don makuek subdistrict, u-thong district, suphanburi province. Ms. ThonglodThongchua has been group leader. This group has been weaving according to the identity of the Tai Song Dam people. There have had 4 types of fabric prepared: cotton, silk, watermelon pattern sarong and sarong. Weaving of this group is inherited for many generations until becoming a dress culture

Weaving process 1) Started by growing cotton or Planting mulberry silk 2) Bring a girl into a thread 3) Weaving a piece of yarn.

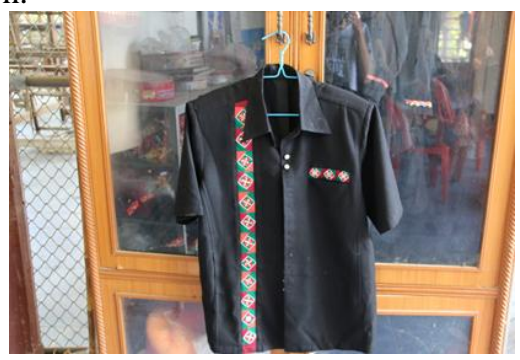

Fig.14Sample product

\subsection{Ancient black tai cultural restoration center}

Located at ban don subdistrict, u-thong district, suphanburi province. The symbols that stand out when they arrive had been traditional house of Tai Song Dam or "huankradongtao". The house has divided into different rooms. In the house has shown appliances clothing in everyday life. Cause called huankradongtao because it has caused by 2 sources:

2.4.1 Turtle has help human beings by helping to teach prayers to god.

2.4.2 Turtle told the god that humans are benevolentcreatures. God sent buffalo to help agriculture. Whenthe buffalo died. Tai Song Dam people put the buffalo horn on the roof. Which is another symbol of the Thai Song Dam.

Traditional house of Tai Song Dam has been a reflection of building a house that compatible with nature and respects nature. 


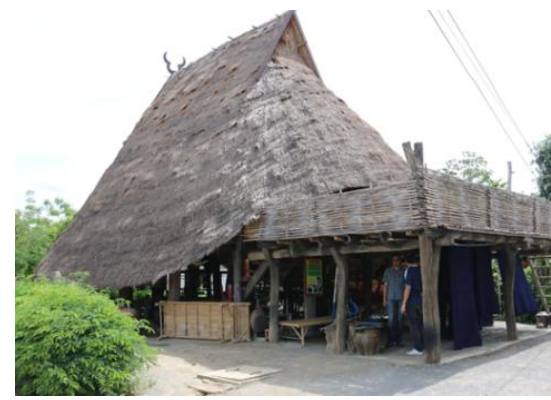

Fig.15huankradongtao

3.Natural resource tourism referred to tourism thatfocuses on the studied of natural resources and plants in U-thong district, consisting of

3.1Suphanburi agricultural extension and development centerLocated at phapphachai subdistrict, u-thong District, suphanburi province. Operated since 2002. On an area of 380 rai. The objective of establishmenthas been to develop work in plant varieties and traincareer in agriculture both in production using technology. Tissue culture in the laboratory, kindergarten distribution of species, planting, promotion, training in various technologies, support for farmers.

In the center has been annual plant-related activities such as the Tulip festival in January, Rose festival in February, Lotus festival in June, Siamese flower festival in August, Sunflower festival in December etc.

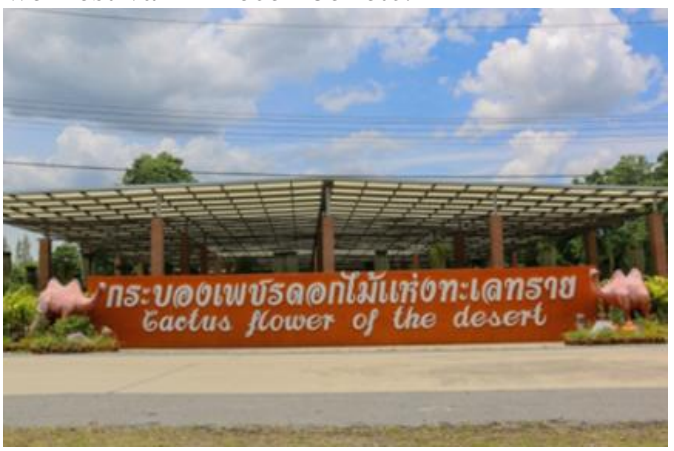

Fig.16Cactus flower of the desert

3.2Phu hang nak rock parkPhu hang nak rock park has been an ancient stone garden that has been tens of thousands of years old. The garden has been naturally beautiful. Stone shapes and patterns can be imagined in various shapes. According to the idea of tourists. On the hill a spring comes out. Has a meander-like appearance. Then flow together to form a source of water has called huai hang nak. This is another place where you can watch the sunset.

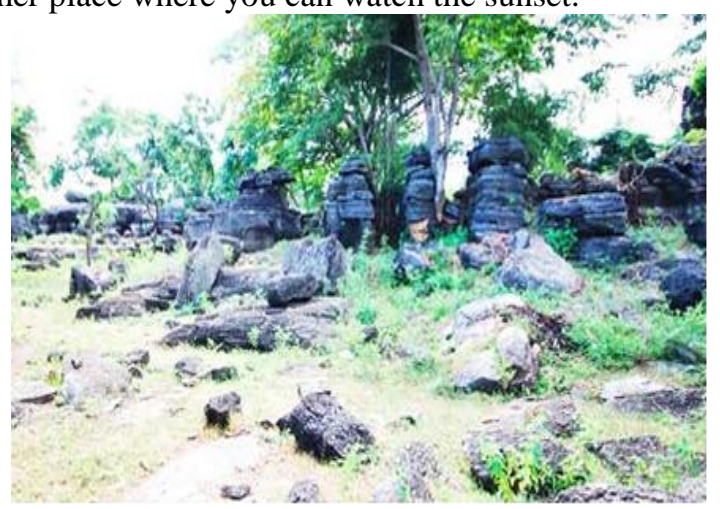

Fig.17Phu hang nak rock park
3.3Phumuang forest park Phumuang forest park has been a natural forest near the u-thong district. During the rainy season, the water in Phumuang waterfall has been abundant. It has been another famous tourist attraction. Within the park can be camped for those who have interested and like the quiet natural atmosphere. Classified that Phumuang forest park has been a natural tourist attraction near the city. Within the park will find a beautiful forest.

Phumuang forest park with an area of approximately 1,725 rai, the area has been a mixed deciduous forest alternating with bamboo ruak. Within the forest park, there have interested things, such as the nature trail, a distance of 1.50 kilometers and takes about an hour and a half to walk.

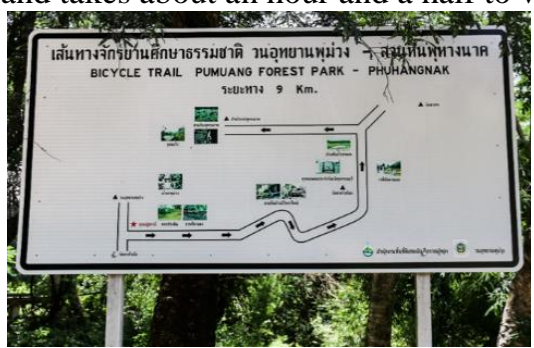

Fig.18 Bicycle trail pumuang forest park- phuhangnak

\section{Discussions}

U-thong district had various attractions many interesting both in history, culture and natural resources. Some places there were still less tourists because used to lack public relations. Public relations have been of great importance to tourism because it has made tourists interested in visiting. Consistent with the research of [6] and [7] saidpublic relations has contributed to tourists' interest in tourism. The public relations were required cooperation from the governmentbecause it has been one of the roles of the government involved in tourism consistent to [8] said the government has involved in public relations, promotion and dissemination of tourism to domestic and foreign tourists.Therefore, the public relations have been very important. It has been in from of a travel guide, pamphlet of map. Currently, the most popular public relations channel has been internet consistent to [9]found today, tourists found tourist information from the Internet.

\section{Recommendations}

\section{A. Recommendations for Practices}

1. There should be more publicity for tourist attractions in U-thong district.

2. Coordinate various departments in supporting tourism in U-thong district.

\section{B. Recommendations for Further Research}

Should study the traditions of each ethnicity in U-Thong District

\section{Conclusion}

In conclusion, the findings from the analysis of qualitative showed although $U$ Thong District has many tourist 
attractions. But some places are very few tourists.Because of the lack of publicity.

\section{References}

[1] S. Wanliphodom, "History of Archeology: Uthong City", Bangkok: Muangboran, 2006.

[2] Krit Won-in and other,"Ancient Glass Bead from U-thon Ancient City Site Central Thailand",Journal of Key EngineeringMaterials. vol.737, pp. 590594, 2017.

[3] Anna Bennett, "The Ancient History of Uthong city of gold: a scientific study of the gold from U Thong", Bangkok: River Books,2017.

[4] I. Pongnak and S. Disatapunahu, "The community identity of the ancient town of $\mathrm{u}$-thong suphanburi province", Veridian EJournal, Slipakorn University. Vol.8, pp.511-523, 2015.

[5] P. Payakwichain, "Grassroots cultural tourism by communities in Thailand",eTAT Tourism Journal. Vol.1, pp.1-7, 2007.

[6] Suwanpimol k, "The Principles of Guide". Bangkok: SangDao,2015.

[7] W. WongWanach, "Tourism geography", Bangkok: Thammasat University.

[8] S. Kanjanakit, "Recreation and tourism industry", Bangkok: Chulalongkorn University.

[9] T. Waewkaew, "Tourism behavior of Thai tourists travelling to Korea of Japan", Masters' degree of Business in Department of General management Faculty of Business administration. Rajamangala University of Technology Thanyaburi, 2014. 